\title{
DIGITAL KNOWLEDGE OF KENYAN SUCCULENT FLORA AND PRIORITIES FOR FUTURE INVENTORY AND DOCUMENTATION
}

\author{
Emily Wabuyele ${ }^{1,2, *}$, Simon Kang'ethe ${ }^{3,4}$ and LeOnard E. NeWton ${ }^{2}$ \\ ${ }^{1}$ National Museums of Kenya, P.O Box 40658, Nairobi 00100, Kenya; ${ }^{2}$ Kenyatta University, P.O \\ Box 43844, Nairobi 00100, Kenya, ${ }^{3}$ East African Herbarium, P.O Box 46166, Nairobi 00100, \\ Kenya; ${ }^{4}$ World Agroforestry Centre (ICRAF), United Nations Avenue, Gigiri, P. O. Box 30677 \\ Nairobi 00100 Kenya
}

\begin{abstract}
Biodiversity inventory in Kenya has been ongoing for about a century and a half, coinciding with the arrival of naturalists from Europe, America, and elsewhere outside Africa. Since the first collections in the mid-to-late $1800 \mathrm{~s}$, there has been a steady increase of plant surveys, frequency of inventory, and discovery of new species that have considerably increased knowledge of faunal and floristic elements. However, as in all other countries, such historical biological collection activities are more often than not, ad $h o c$, resulting in gaps in knowledge of species and their habitats. While Kenya is relatively rich botanically, with a succulent flora of about 428 taxa, it is apparent that the list is understated owing to, among other factors, difficulty of preparing herbarium material and restricted access to some sites. This study investigated completeness of geographic knowledge of succulent plants in Kenya, with the aim of establishing species distribution patterns and identifying gaps that will guide and justify priority setting for future work on the group. Species data were filtered from the general BRAHMS database at the East African Herbarium and cleaned via an iterative series of inspections and visualizations designed to detect and document inconsistencies in taxonomic concepts, geographic coordinates, and dates of collection. Eight grid squares fulfilled criteria for completeness of inventory: one in the city of Mombasa, one in the Kulal-Nyiro complex, one in Garissa, one in Baringo, and four grid squares in the Nairobi-Nakuru-Laikipia area. Poorly-known areas, mostly in the west, north, and north-eastern regions of the country, were extremely isolated from wellknown sites, both geographically and environmentally. These localities should be prioritised for future inventory as they are likely to yield species new to science, species new to the national flora, and/or contribute new knowledge on habitats. To avoid inconsistencies and data leakage, biodiversity inventory and documentation needs streamlining to generate standardised metadata that should be digitised to enhance access and synthesis.
\end{abstract}

Key words: Succulent plants, well-known sites, data leakage, inventory, species diversity

Kenya lies astride the Equator, and covers a total land area of $582,646 \mathrm{~km}^{2}$ at latitudes of $5^{\circ} \mathrm{N}-$ $5^{\circ} \mathrm{S}$ and longitudes $34-41^{\circ} \mathrm{E}$ along the northeastern seaboard of Africa. The country's topography varies from sea level in the coastal zone with coral reefs and mangrove swamps; the Rift Valley lake system; the low-lying plains and Chalbi Desert in the north and northeast; to scattered upland massifs such as Mount Elgon, the Mau Escarpment, Cherangani Hills, and the Aberdare ranges, including the highest point at $5194 \mathrm{~m}$ on Mount Kenya (Lucas, 1968; MEWNR and RDA, 2015).

The climate across Kenya is heavily influenced by elevation, its equatorial location, proximity to the Indian Ocean to the east, Lake Victoria to the west, and the central highlands. Average annual rainfall and seasonality vary widely with elevation; a meagre $150 \mathrm{~mm}$ are received in the low-lying drylands in the north and northeast, while over $2500 \mathrm{~mm}$ are received at high elevations such as on the slopes of Mount Kenya. Two rainy seasons are experienced each year: the short rains from October to December, and long rains from March to May. Temperatures vary with relief, season, rainfall, and cloud cover. The northern and eastern lowlands reach maximum average temperatures of more than $35^{\circ} \mathrm{C}$ and the central highlands of less than $18^{\circ} \mathrm{C}$; sub-zero temperatures are experienced during the nights in the alpine zones of the highest peaks (Lucas, 1968).

Phytogeographically, the country sits at the confluence of five major regions of White (1983); the zone between the Rift Valley and the coastal belt belongs to the Somalia Masai Regional Centre 
of Endemism (RCE), an extensive region that is only occasionally broken by the Afro-montane archipelago-like RCE to which the highlands on both sides of the Rift Valley belong. The western parts of the country are split between the Sudanian RCE and the Lake Victoria Regional Mosaic (RM), whereas the coastal strip belongs to the Zanzibar-Inhambane RM. In tandem with climatic patterns of Kenya, the vegetation ranges from almost bare rock and sand dunes in the arid zones, through Acacia-Commiphora bushland to grassland with scattered trees, dry highland forests, tropical rainforests, and alpine vegetation at high elevations (Maundu et al., 1999; Beentje and Smith, 2001).

Although not as diverse biologically as countries in the American or Asian tropics, Kenya holds a large diversity of species, estimated at 35,000 taxa of plants, animals, and microorganisms, many of which are endemic. This diversity has been attributed to long periods of geological stability, as well as the variety of microhabitats that exist across the country (Hepper, 1979; Nordal et al., 2001). A recent analysis of biodiversity hotspots for Kenya by the Ministry of Environment, Water and Natural Resource, estimated plant diversity at just over 7000 species of vascular plants, belonging to 1720 genera and 240 families (MEWNR and RDA, 2015). According to that report, most species are concentrated in three key areas that harbour exceptionally high plant diversity: Mount Elgon in the West, Nairobi and its environs in the central highlands, and the coastal strip bordering the Indian Ocean, with 650-950 species per square degree of area. Isolated mountain peaks such as Marsabit and Kulal in the northeast are rich in endemic species. The coastal forests and some of the isolated mountains in southeastern Kenya are part of the Eastern Arc and Coastal Forests Hotspot and the Afromontane Hotspots, respectively (Myers et al., 2000; Mittermeier et al. 2005).

To a large extent, knowledge of biodiversity in general and plants in particular is dictated by the intensity of field surveys and inventory. For instance Kuper et al. (2006) noted that, despite a relatively good taxonomic understanding of vascular plants, knowledge of geographic distribution of species is generally poor, even in large herbaria where $75 \%$ of the species are represented by less than 10 collection records. As noted by Colwell and Coddington (1994), traditional collection methods used in biodiversity surveys for museums and herbaria may intend to collect all species, but such a goal is neither easy to attain nor to monitor and measure. As such, the geographic distribution of tropical plant and animal diversity is still poorly documented, especially at spatial resolutions of practical use for conservation.

As with neighbouring countries in the region, biodiversity inventory in Kenya has been ongoing for just about a century and a half, coinciding with the arrival of naturalists from Europe, North America and elsewhere outside of Africa. Since acquisition of the earliest collections on expeditions in the mid-to-late 1800s (Newton, 2004a), plant collections and surveys have shown a steady increase, with discoveries of new species and documentation of occurrence patterns that have increased knowledge of faunal and floristic elements. However, preliminary analyses of field sampling patterns suggest bias towards collecting in accessible localities that are not necessarily the most important biodiversity hotspots of the country (Beentje and Smith, 2001). Furthermore, most of the information remains inaccessible beyond the immediate research and scientific communities, effectively inaccessible in analogue formats in museum and herbarium cabinets: only $17-20 \%$ of specimens worldwide are available in sharable formats (Ariño, 2010), further aggravating the problem of inadequate species inventory.

Of the total floristic diversity in Kenya, about $5 \%$ of Kenyan species are succulent in nature. Newton (2003) listed 428 taxa, representing 370 species, 51 genera, and 20 families, of succulent plants in the country. This concentration of species is high compared to global totals of $\sim 10,000$ species (El-Ghanie et al., 2014). As reported by Sajeva and Costanzo (1994), succulence is found in over 30 plant families globally, the largest being Aizoaceae, Cactaceae, Crassulaceae, Euphorbiaceae, Apocynaceae, Agavaceae, Asphodelaceae, (now Xanthorrhoeaceae), Chenopodiaceae, and Portulacaceae. In Africa, succulent plants are distributed in most vegetation types except the tall forests of West Africa and the Miombo woodlands (Oldfield, 1997).

Like the rest of the national and regional flora, conservation of Kenyan succulent plants is hampered by a suite of knowledge gaps, including 
difficulties associated with description, identification and general taxonomic documentation of species. Preparation of specimens of succulent plant species requires additional skill and patience (Bridson and Forman, 1989; Newton, 1995), which more often than not are inadequate amongst general plant survey and inventory teams. In addition, probable key sites of diversity and endemism for succulent plant species (the arid and semi-arid regions) are hard to access, both logistically and politically. Succulent species nonetheless deserve special attention, as they grow in habitats with a fragile ecological equilibrium where harsh environmental conditions lead to slow rates of growth and low reproductive rates, including seed viability as low as $0.1 \%$ for some species (Sajeva and Costanzo, 1994). In addition, owing to commercial interest, unregulated removal of mature plants may result in unsustainable reproductive rates and accelerate extinction of species.

In this paper, we therefore hypothesize that the Kenyan list of succulent taxa is understated, and far from complete, owing to, among other factors, difficulty of preparation of herbarium material and restricted access to key sites. We explore a relatively detailed data set that documents known occurrences of succulent plant species, using techniques designed to assess completeness of geographic knowledge of succulent plants in Kenya. Our aim is to establish species' distribution patterns and identify knowledge gaps that can guide and justify priority setting for future work on this iconic functional group.

\section{METHODS}

The East African Herbarium (EA), where large numbers of specimens and associated data records for Kenya, Uganda, and Tanzania are housed, has over the last two decades made progress in digitisation of its vascular plant specimen data as part of routine information management activities. To date, information has been captured from $>200,000$ specimens using the Botanical Research and Herbarium Management Software ${ }^{1}$. Apart from records associated with specimens housed at the EA, the database includes $>10,000$ records from the Kew Herbarium that have been repatriated as part of collaborative data

\footnotetext{
${ }^{1}$ http://herbaria.plants.ox.ac.uk/bol/brahms/Software.
}

mobilisation initiatives. Data corresponding to succulent plant species were prioritised for digitisation as a thematic group of interest in conservation and trade across the region; as such, we estimate that $90 \%$ of succulent plant records at the EA have now been captured and are treated in this report. General information on species numbers for the country was collated from existing published sources.

Prior to analysis, data were cleaned via an iterative series of inspections and visualizations designed to detect and document inconsistencies. (1) We explored concentrations of sampling by calculating species densities based on raw specimen counts. (2) We created lists of unique names in Excel, and inspected them for repeated versions of the same taxonomic concepts: misspellings, name variants, different versions of authority information, etc. Such duplicate names were flagged, checked via independent sources, and corrected to produce single scientific names that correctly referred to single species taxa. (3) We checked for geographic coordinates that fell outside of the country, but which were referred to as falling within Kenya. (4) Within the country, we checked for consistency between textual descriptions of major area (divisions) and locations of geographic coordinates. In each case, where possible, we corrected the data record; where no clear correction was possible, we discarded data, recording losses at each step in the cleaning process. Finally, (5) we discarded data records for which information on year, month, or day of collection was lacking and created a unique 'stamp' of time as year_month_day.

We then aggregated point-based occurrence data to $0.5^{\circ}$ spatial resolution across the country. This spatial resolution was the product of a detailed analysis of balancing benefits of aggregating data (i.e., larger sample sizes), versus the loss of spatial resolution that accompanies broader aggregation areas that can make important geographic features imperceptible (i.e., $1^{\circ}$ resolution is a square $\sim 110 \mathrm{~km}$ on a side). Details of this procedure are provided by Sousa-Baena et al. (2014) and explored and analyzed in more detail for African examples in Idohou et al. (2015) and Koffi et al. (2015).

We produced the aggregation grid shapefiles in the Vector Grid module of QGIS, version 2.4; added the coarse-resolution grid identification 


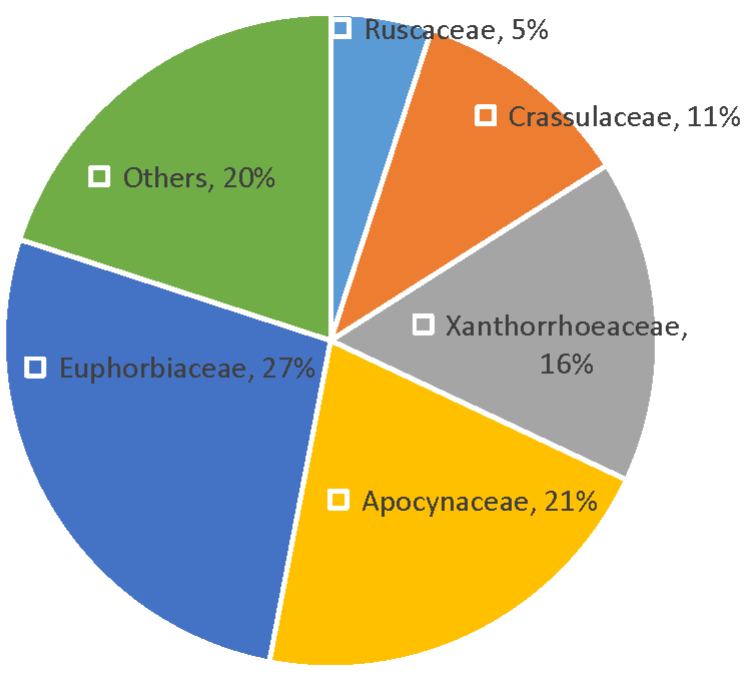

Figure 1. Species diversity amongst succulent plant families in Kenya, based on records at the East African Herbarium and published sources.

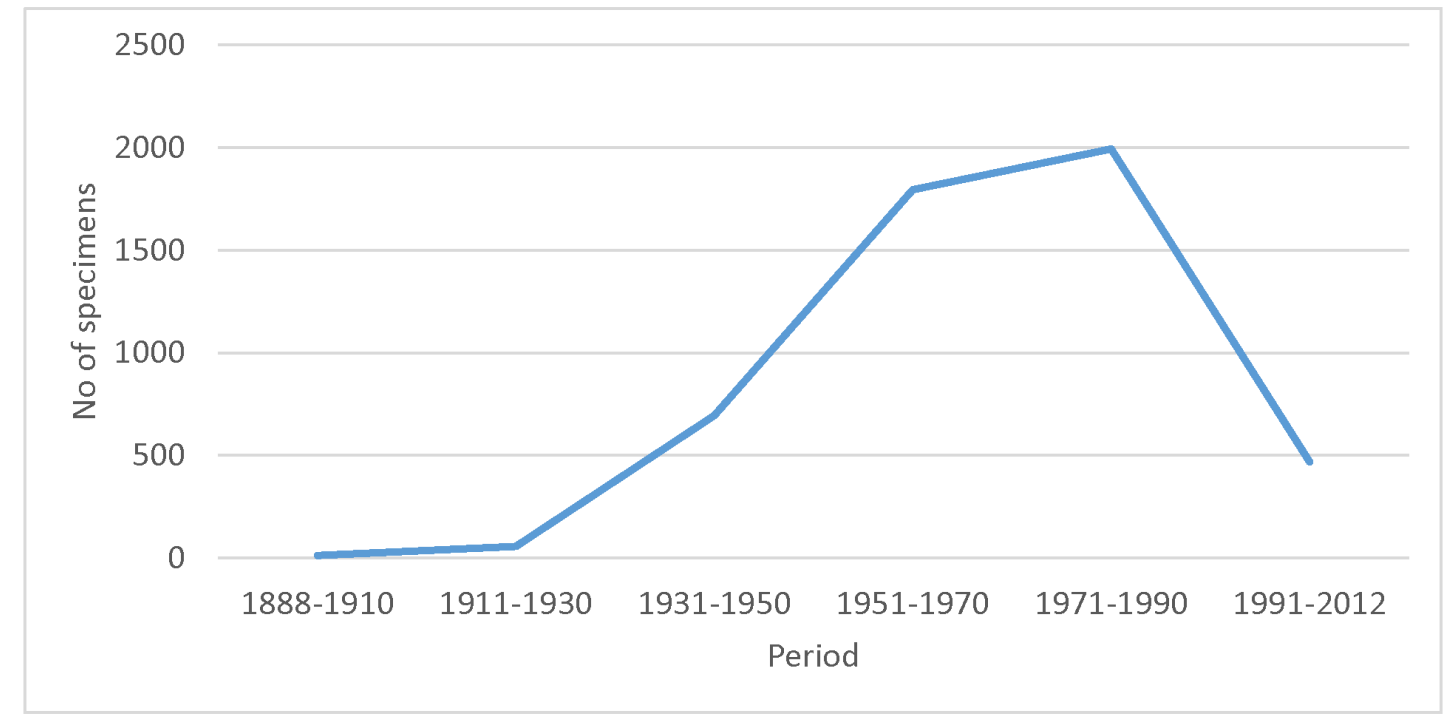

Figure 2. Collecting trends of succulent plant specimens between the years 1888 and 2012. 
codes to each occurrence datum; and aggregated each datum into the coarse-resolution aggregation squares. In Excel, we explored associations between data on species identity, time, and aggregation grid square. We calculated (1) the total number of records $(N)$ available from each grid square; (2) the total number of species recorded from each grid square $\left(S_{o b s}\right)$; and (3) the number of species detected on exactly one day (a), and (4) the number of species detected on exactly two days (b). Using equations provided by Chao (1987), we calculated the expected number of species $\left(S_{\text {exp }}\right)$, as $S_{\text {exp }}=S_{o b s}+a^{2} / 2 b$, and inventory completeness (C) as $C=S_{\text {obs }} / S_{\text {exp }}$.

We explored plots of $C$ versus $N$ to assess practical, appropriate, and adequate definitions of relatively completely versus incompletely inventoried grid squares. Once we had established criteria for which grid squares could be considered as wellsampled, in QGIS, we linked the table with the grid square statistics (i.e., $N, S_{o b s}, S_{\text {exp }}, C$ ) to the aggregation grid, and saved this file as a shapefile. Applying the criteria for 'well-sampled' (i.e., $C>$ 0.5 and $N>10$ ), we created a shapefile of wellsampled grid squares, which we in turn converted to raster (geotif) format using custom scripts in $\mathrm{R}$ (R Core Team, 2013). This raster coverage was the basis for our identification of gaps. We then used the Proximity (Raster Distance) function in QGIS to summarize geographic distance across the country to any well-sampled grid square.

To create a parallel view of environmental difference from well-sampled areas (i.e., how different the climate is from that of the most similar well-surveyed grid square), we plotted 5000 random points across the country, and used the Point Sampling Tool in QGIS to link each point to the geographic distance raster, and to raster coverages $\left(2.5^{\prime}\right.$ spatial resolution) summarizing annual mean temperature and annual precipitation drawn from the WorldClim climate data archive (Hijmans et al., 2005). We exported the attributes table associated with the random points, and analysed further in Excel. We first standardized the values of each environmental variable to the overall range of the variable as $\left(x_{i}-\right.$ $\left.x_{\min }\right) /\left(x_{\max }-x_{\min }\right)$, where $x_{i}$ is the particular observed value in question.

We then created a matrix of Euclidean distances in the two-dimensional climate space, relating all of the points with a geographic distance
$>0$ to all of the points with geographic distance of zero. The latter represent points falling in wellsampled grid squares, whereas the former are scattered across the entire country; points falling in well-sampled grid squares were assigned (by definition) environmental distances of zero. Finally, the environmental distances were imported into QGIS, and linked back to the random points shapefile to create a new shapefile with broad sampling across the country, with a $z$-value that is the environmental distance associated with that point. To convert this vector-format dataset into raster format, with values interpolated across the entire region, we used a second-degree inversedistance weighting approach, although many other interpolation approaches could be explored.

\section{RESULTS}

On the basis of available literature and records in the EA database, the succulent flora of Kenya is dominated by species of five families: Euphorbiaceae, Apocynaceae (subfamily Asclepiadoideae), Xanthorrhoeaceae (genus Aloe), Crassulaceae and Ruscaceae. These families together account for $80 \%$ of Kenya's succulent flora. Several other families (Malvaceae, Cactaceae, Pedaliacaeae and Icacinaceae) are represented by single species each; the Aizoaceae (Mesembryanthemaceae), a predominantly South African family, is represented by two species of the genus Delosperma. Many species listed for Kenya in the Flora and other publications were not represented by any records in the dataset analyzed.

This study indicated that collecting activity of succulent plants began in the latter part of the nineteenth century: the first record of a succulent species was made in 1888 . This early period lasted until about 1910, within which time only 12 specimens of succulent plants were collected. Subsequently, however, collecting activity accelerated, with peaks in the 1970s and 1990s. Over these years, numbers of collections increased, with annual averages of 90-100 specimens. This activity, however, dwindled to a meagre average of about 25 specimens per year in more recent years.

Generally, the raw data showed close spatial correspondence to the existing road network and major settlements and urban areas. Collection 'hotspots' of the country thus include areas neighbouring the capital city Nairobi, the central, western and coastal regions, and mountain peaks in 


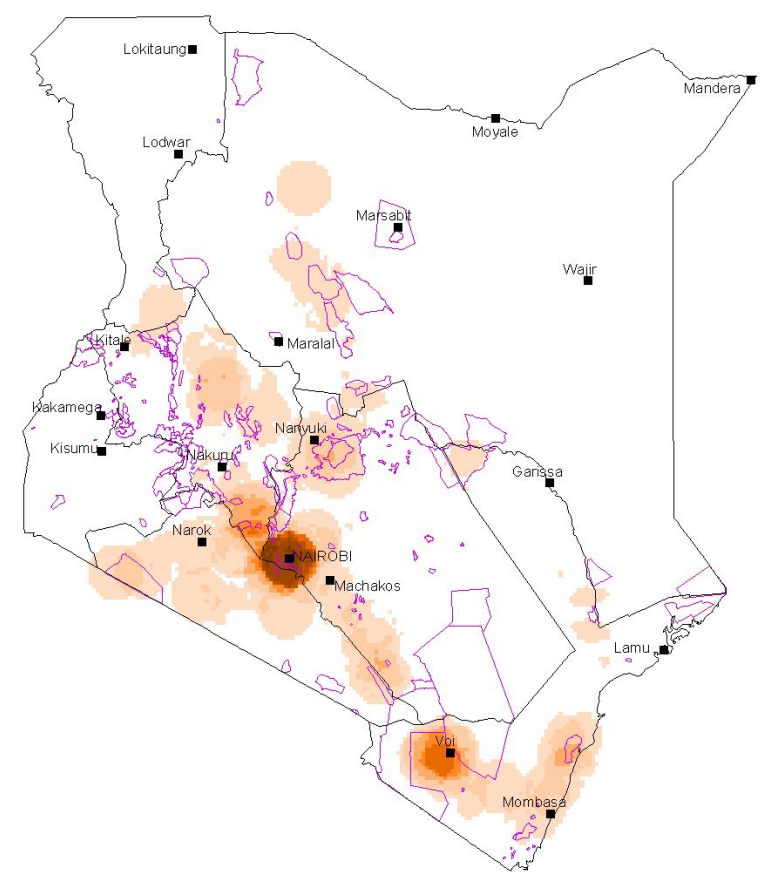

Figure 3. Spatial patterns of succulent plant collecting vis a vis existing protected areas (black outlines) in Kenya. Darker (brown) zones have highest record density; lighter (pink) zones have lower record density. White zones were not represented by collections in datasets available for this study.

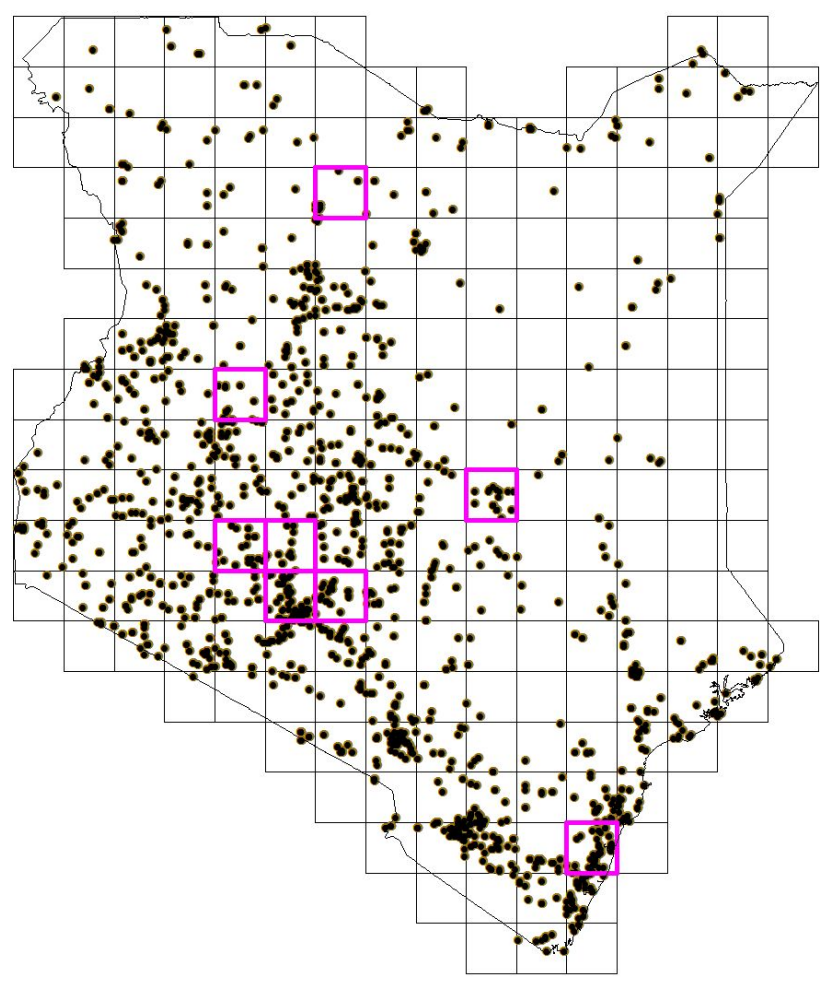

Figure 4. Well-known grid squares (purple colour outlines) in relation to collecting sites (black dots) revealing areas of relatively complete inventory of succulent plants in Kenya. 
the southeastern part of the country. Areas to the north, northeast and northwest are visibly undersampled except for scattered mountain peaks such as Kulal, Nyiru and the Ndotos. Of interest is the fact that most of the sampling 'hotspots' fall outside the country's conservation areas, such that little current information is available for conservation areas.

In the course of data cleaning, $\sim 20 \%$ of the records were discarded in light of gaps in information content and inconsistencies; the final dataset contained 4304 records of succulent plant specimens collected from across the country. The total area of Kenya was contained in 206 grid squares, $31.5 \%$ of which had no succulent plant records. Eight grid squares fulfilled criteria for completeness of inventory: one centred on the coastal city of Mombasa, one in the Kulal-Nyiru complex in the north, one at Garissa in the northeast, one at Baringo in the northwest and four grid squares in the Nairobi-Nakuru-Laikipia complex. In between well-known sites, broad regions constituted gaps in Kenya's succulent plant inventory.

Measurement of geographic distance from well-known grid squares revealed the most farflung under-sampled regions; the Turkana and the Moyale regions bordering Ethiopia were the most isolated. The next level of isolation included the northeastern zone in general: Wajir, Marsabit, Mandera (Moyale), and Tana River counties bordering Somalia in the east and the Lake Victoria basin in the west, the region between the Nairobi area and other well-sampled grid squares showed some geographic isolation as well.

Roughly congruent patterns were observed in terms of environmental distance from wellsampled sites: maximum environmental difference was evident for the Turkana region, Wajir and Mandera in the north to northeast, the Tana RiverMalindi complex on the north coast and the Lake Victoria basin in the west. Notable here is the fact that some geographically distant sites, such as those along the border with Ethiopia (Mandera), South Sudan (Illemi triangle), and Tanzania (Kilimanjaro and Amboseli) were not markedly distinct in environmental terms.

\section{DISCUSSION}

While specimens are undoubtedly the most accurate primary research archives documenting biological diversity on Earth, they are inevitably subject to spatial bias resulting from ad hoc spatial accumulation of samples, with most data coming from easy-access localities (Ponder et al, 2001; Reddy and Davlos, 2003; Grand et al., 2007). In addition, botanists tend to concentrate research efforts in botanically diverse (hence interesting) areas, generally avoiding species-poor areas (Soria-Auza and Kessler, 2008). Finally, and more specifically to this paper, succulent plants are notoriously difficult to prepare and preserve (Bridson and Forman, 1989; Newton, 1995), such that numbers of specimens of these groups tend to be lower than in other taxa.

In line with global trends of taxonomic diversity, the Kenyan succulent flora is dominated by the large families Euphorbiaceae, Apocynaceae (subfamily Asclepiadoideae), Xanthorrhoeaceae, and Crassulaceae (Oldfield, 1997). Similarly, Aizoaceae and Cactaceae, predominantly South African and South American in terms of biogeographic origins and centers of diversity, respectively, are poorly represented, with only two and one species, respectively. The country also holds rich diversity of the otherwise small family Ruscaceae, represented by species of the genera Sansevieria and Dracaena. (Figure 1).

According to Newton (2004a), the earliest specimens of succulent plants were collected by Thomas Wakefield, an English missionary who lived on the Kenyan coast for over 20 years beginning around 1862. This period (Figure 2) was one of little or no knowledge of the Kenyan flora, and is part of what has been termed as the "heroic period,' during which scientists had to brave dangerous terrain to access the largely unexplored African interior (Gillett, 1962). In subsequent years, however, further opening up of the interior, and particularly the arrival of trains and motor vehicles facilitated plant survey and collecting expeditions. One notable development in the 1930s was establishment of the Corydon Museum Herbarium in Nairobi, and hiring of its first keeper, who actively carried out collecting missions that added at least 4000 specimens to the collection (Newton, 2004b). In addition, interest in the regional flora accelerated, leading to commencement of preparation of the Flora of Tropical East Africa in the early 1950s. Activities of the Flora project peaked in the 1990 s, by which time almost $70 \%$ of the family accounts had been published 


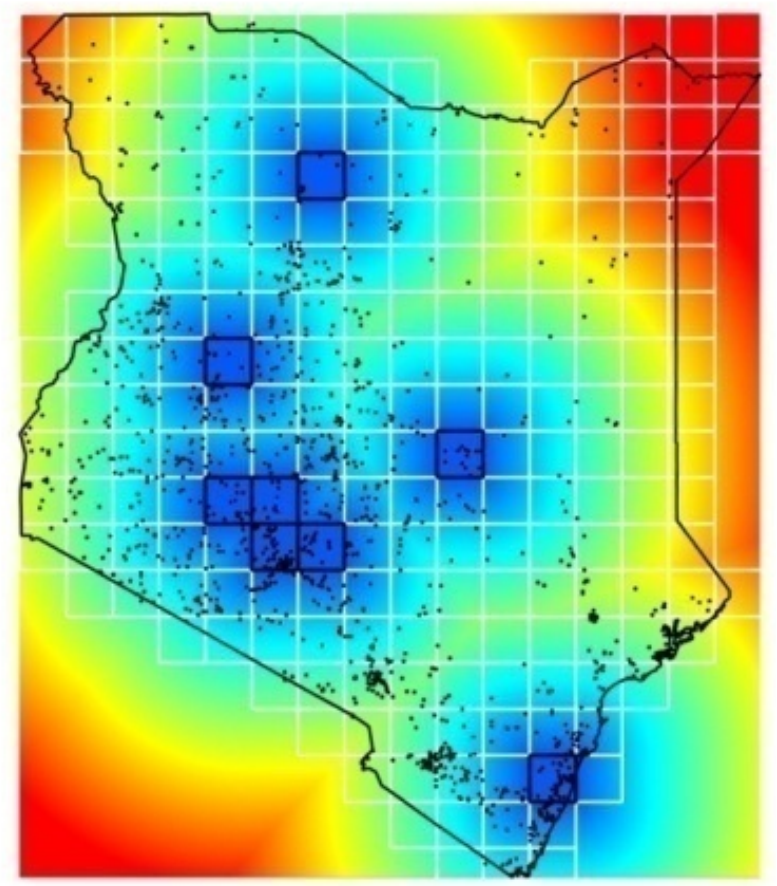

Figure 5. Geographic distances across Kenya to well-inventoried grid squares. Dark blue zones are within well-known areas, light blue to yellow shows middle to high distances; red zones are extremely isolated from well-inventoried grid squares.

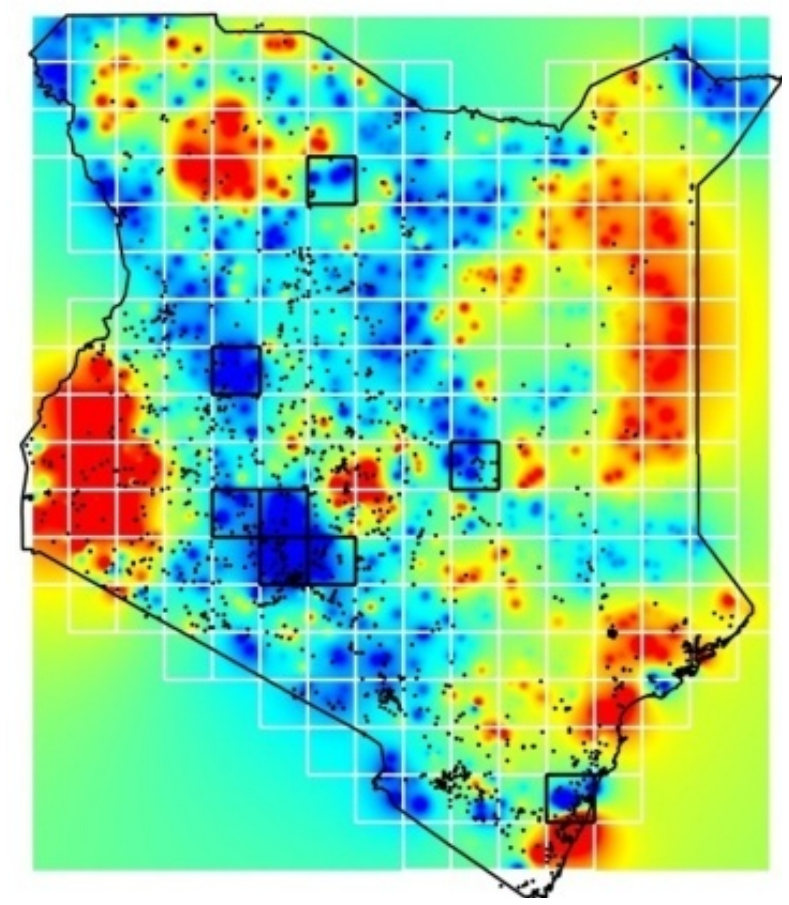

Figure 6. Environmental distance showing ecological isolation of little known, poorly inventoried sites. Dark blue zones are within well-known areas, light blue to yellow shows middle to high distances; red zones are extremely distinct from well-inventoried grid squares. 
(Beentje and Smith, 2001; Newton, 2004a). However, field collection decelerated in succeeding years, probably owing to difficulties in the research permitting process, which remain almost prohibitive to date, among other impediments.

Based on our analyses, three well-known sites-the Kulal-Nyiro complex in the north, Garissa in the northeast, and Baringo in the northwest - are largely semi-arid to arid in nature, and therefore are good confirmation of universal patterns of succulent plant habitat preferences. Oldfield (1997) noted that the Somalia-Maasai $\mathrm{RCE}$, to which most of this region belongs, has been documented as being especially diverse for succulent taxa. However, expansive geographic and environmental gaps exist among these few well-known sites, raising the possibility that concentrated survey efforts sited strategically in these gaps would result in more species new to science, or new to the flora, or contribute hitherto undocumented information on succulent plant diversity patterns.

The rest of the well-known sites, the NairobiNakuru-Laikipia complex and that centred on Mombasa at the coast, certainly reflect both ease of access and the concentration of infrastructure, including research institutions, personnel, and botanical gardens and herbaria. Two of the largest herbaria, EA and the Herbarium of the University of Nairobi, are located in Nairobi; the Nairobi Botanic Garden, among the oldest such facilities in the country, is also located in Nairobi. The coastal region has benefited from research capacity generated through the Coast Forest Survey Programme of the National Museums of Kenya for over two decades. As such, these regions are wellknown owing simply to concentrated sampling and documentation of the flora.

While the plant inventory completeness patterns documented in this study are obviously determined by a combination of the natural richness of sites, as well as ease of access and proximity to research infrastructure, it is important to recall that only a fraction of the existing succulent plant data was available for the present analyses. Some of the existing data was either not digital, had no geographic coordinates, or had no dates of collection, causing extensive 'leakage' from an otherwise more sizeable dataset. This reduction of Digitally Accessible Knowledge therefore calls for need to improve documentation protocols and standards, including the processes of specimen collection, preparation, and storage, and subsequent management, digitisation, improvement, and publication of associated data. Furthermore, the data analysed here correspond to collections held in only two herbaria, neither of which has been digitised completely. As observed by Morat and Lowry (1997), gaps such as those exhibited in the succulent flora of Kenya dataset emphasize the need to take advantage of available expertise to verify, compare, and standardise information to generate reliable accounts of floristic elements of various regions.

\section{CONCLUSIONS AND RECOMMENDATIONS}

The history of succulent plant collecting is apparently closely associated with patterns of general floristic exploration across East Africa, and in Kenya in particular, which undoubtedly is influenced by ease of access to localities. As the debate on climate change continues, it will be critical to reflect on the wealth of biodiversity of the region, and identify strategies for mitigation that will enhance resilience and survival of ecosystems in the face of the anticipated increased temperature and reduced rainfall. Importantly, it will be critical to re-evaluate the extent to which unique elements of biodiversity, such as its succulent flora, are protected in the present conservation area network.

As demonstrated in this study, knowledge of succulent plants in Kenya is far from complete, hence the need for focused survey, inventory and documentation especially in sites that have been shown to be distant geographically and ecologically. With the writing of the Flora out of the way, the time is ripe for development of research programmes that will translate existing information into conservation policy and action, and mobilise resources to enable survey and inventory teams to ramp up collection activity in isolated and little-known sites across the country. Increased digitisation and publication (i.e., data sharing via data portals such as the Global Biodiversity Information Facility ${ }^{2}$ of information should be priority for EA and herbaria in general to enhance utility of research material. Digitisation and open sharing of data-in effect data 'repatriation'-from more herbaria with significant

\footnotetext{
${ }^{2}$ http://www.gbif.org.
} 
Kenyan holdings, including Missouri Botanical Garden, Botanic Garden and Botanical Museum of Berlin-Dahlem, the Smithsonian Institution, and others, is also crucial.

\section{ACKNOWLEDGMENTS}

We thank the Biodiversity Informatics team, National Museums of Kenya, led by Dr. Geoffrey Mwachala, Director of Research and Collection, for sustained efforts in digitising collections of the Museums. We thank the East African Herbarium for permission to use the plants database, and Kew Gardens for their efforts in digitising and sharing their data. Capacity building for this assessment was provided by the University of Kansas Biodiversity Informatics Training Curriculum, funded by the JRS Biodiversity Foundation.

\section{REFERENCES}

El-Ghani, A. M., A. Soliman and R. A. El-Fatta. 2014. Spatial distribution and soil characteristics of the vegetation associated with common succulent plants in Egypt. Turkish Journal of Botany 38: 550565.

Ariño, A. H. 2010. Approaches to estimating the universe of natural history collections data. Biodiversity Informatics 7: 81-92.

Beentje, H. and S. Smith. 2001. FTEA and after. In (Eds.). E. Robbretht, J. Degreef, and I. Friis. Plant systematics and phytogeography for the understanding of African biodiversity. Proceedings of the XVIth AETFAT Congress, held at the National Botanical Garden, Belgium, 2000.

Bridson D. and L. Forman.1989. The Herbarium Handbook. Revised Edition, 303 pp. Royal Botanic Gardens, Kew, UK.

Chao, A. 1987. Estimating the population size for capture-recapture data with unequal catchability. Statistica Sinica 10: 227-246.

Colwell, R. K. and J. A. Coddington. 1994. Estimating terrestrial biodiversity through extrapolation. Philosophical Transactions of the Royal Society of London 345:101-118.

Gillett, J. B. 1962. The history of the botanical exploration of the area of "The Flora of Tropical East Africa." Comptes Rendus IV Réunion AETFAT. Pp 205-229.

Hepper, F. N. 1979. Second edition of the map showing extent of floristic exploration in Africa South of the Sahara, published by AETFAT. In G. Kunkel (ed.), Taxonomic Aspects of African Economic Botany. Proceedings of the IX Plenary Meeting of AETFAT. Las Palmas de Gran Canaria. Pp 157162.
Hijmans, R. J., S. E Cameron, J. L. Parr, P .G. Jones and A. Jarvis. 2005. Very high resolution interpolated climate surfaces for global land areas. International Journal of Climatology 25: 1965-1978.

Idohou, R., A. H. Ariño, A. E. Assogbadjo, R. G. Kakai, G. K. Romain, B. Sinsin. 2015. Knowledge of diversity of wild palms (Arecaceae) in the Republic of Benin: finding gaps in the national inventory by combining field and digital accessible knowledge. Biodiversity Informatics 10: 45-55.

Koffi, K. J., A. F Kouassi, C. Y. A. Yao, A. Bakayoko, I. J. Ipou and J. Bogaert. 2015. The present state of botanical knowledge in Côte D'ivoire. Biodiversity Informatics 10: 56-64.

Küper, W., W. Sommer, J. H., Lovett, J. C. and W. Barthlott. 2006. Deficiency in African distribution data-missing pieces of the puzzle. Botanical Journal of the Linnaean Society 150: 355-368.

Lucas, G. L. 1968. Kenya. Acta Phytogeographica Suecica 54: 152-163.

Maundu, P. M., G. W. Ngugi and H. S. Kabuye. 1999. Traditional food plants of Kenya. National Museums of Kenya, Nairobi. Kenya.

MEWNR and RDA. 2015. Kenya Biodiversity Atlas Ministry of Environment, Natural Resources and Regional Development Authorities. Nairobi, Kenya.

Mittermeier, R. A., P. R. Gil, M. Hofman, J. Pilgrim, T. Brooks, C. G. Mittermeier, J. Lamoreux and G. A. B. da Fonseca. 2005. Hotspots revisited: Earth's biologically richest and threatened terrestrial ecoregions. Conservation International, Washington, D.C.

Morat, P. and P. Lowry. 1997. Floristic richness in the Africa Madagascar region: a brief history and perspective. Adansonia 19: 101-115.

Myers, N., R. A Mittermeier, C. G Mittermeier, G. A. B. Da Fonseca and J. Kent. 2000. Biodiversity hotspots for conservation priorities. Nature 403: 853-858.

Newton, L. E. 2003. A Check-list of Kenyan Succulent plants. Succulenta East Africa, Nairobi, Kenya.

Newton, L. E. 2004a. The history of succulent plants in Kenya. Succulenta East Africa, Nairobi, Kenya.

Newton, L. E. 2004b. The first herbarium botanist in Nairobi. Journal of East African Natural History 93: 49-55.

Newton, L.E. 1995. Making herbarium specimens. Ballya 2: 1-3.

R Development Core Team 2008. R: A language and environment for statistical computing. R Foundation for Statistical Computing, Vienna, Austria. ISBN 3-900051-07-0. ${ }^{3}$

\footnotetext{
${ }^{3} \mathrm{http}: / /$ www.R-project.org.
} 
Nordal, I., Sebsebe Demissew and E. S. Odd. 2001. Endemism in groups of geophytes (Liliiflorae). Biologiske Skrifter 54: 247-258.

Oldfield, S. (Ed.). 1997. Cactus and succulent plantsstatus survey and conservation action plan. IUCN/SSC cactus and succulent specialist Group. IUCN. Switzerland and Cambridge, UK.

Ponder, W. F., G. A. Carter, P. Flemons, and R. R. Chapman. 2001. Evaluation of museum collection data for use in biodiversity assessment. Conservation Biology 15: 648-658.

Reddy, S., and L. M. Davalos. 2003. Geographical sampling bias and its implications for conservation priorities in Africa. Journal of Biogeography 30: 1719-1727.

Sajeva, M., and M. Costanzo. 1994. Succulents: the illustrated dictionary. Cassell, London UK.
Soria-Auza, R. W., and M. Kessler. 2008. The influence of sampling intensity on the perception of the spatial distribution of the spatial distribution of tropical diversity and endemism: a case study of ferns from Bolivia. Diversity and Distributions 14: 123-130.

Sousa-Baena, M. S., L. C. Garcia and A. T. Peterson. 2014. Completeness of digital accessible knowledge of the plants of Brazil and priorities for survey and inventory. Diversity and Distributions 20: 369-381.

White, F. 1993. The vegetation of Africa. A descriptive memoir to accompany the UNESCO/AETFAT/ UNSO vegetation map of Africa/ UNESCO, Paris. 